\title{
Acromegaly with normal pituitary MRI
}

\author{
L D Ranasinghe ${ }^{1}$, K D Liyanarachchi ${ }^{2}$, N P Somasundaram ${ }^{3}$
}

Sri Lanka Journal of Diabetes, Endocrinology and Metabolism 2015; 5: 107-110

\begin{abstract}
Acromegaly is commonly caused by a growth hormone $(\mathrm{GH})$ secreting pituitary adenoma, which is often evident on pituitary imaging by the time of presentation. Here we describe 4 patients with acromegaly who had normal MRI of the pituitary at the time of diagnosis. Contrast enhanced computer tomography (CECT) chest and abdomen were also normal. All 4 patients were females and aged 45, 53,69 and 70 years. They had acromegaloid features of varying severity and duration. Dynamic magnetic resonance imaging (MRI) was performed in 3 patients, which revealed pituitary microadenomas in all 3 of them. This highlights the heterogenous behavior of $\mathrm{GH}$ secreting tumours and the value of dynamic MRI in visualizing microadenomas.
\end{abstract}

Key words: acromegaly, microadenoma, pituitary, contrast enhanced computer tomography.

\section{Introduction}

Acromegaly is a progressive multi system disease associated with significant morbidity and nearly 2 fold increased mortality $(1,2)$. Usually, it is caused by a growth hormone $(\mathrm{GH})$ secreting pituitary adenoma. Ectopic source is rare and accounts for $<1 \%$ cases ( 3 ). Since the diagnosis of acromegaly is often delayed by an average of 4-10 years, pituitary adenomas are often large and visible on MRI. When pituitary imaging is normal, localization of GH source becomes a challenge, especially in resource poor setting where growth hormone releasing hormone (GHRH) assay is not available.

\section{Case 1}

A 53 year old lady with hypertension and dyslipidaemia presented with symptoms suggestive of hypothyroidism such as lethargy, constipation, weight gain, cold intolerance and deepening of voice over a period of 1 year. She had a past history of bilateral osteoarthritis of knees and left sided carpal tunnel syndrome, which required decompression. She also had features suggestive of obstructive sleep apnea. On examination, she had acromegaloid features such as coarse facial appearance with prominent supra orbital ridge, enlarged nose, lips and prognathism (Figure 1-No.1). She did not have a goiter. Oral glucose tolerance test (OGTT) showed non suppressed GH, confirming the diagnosis of acromegaly. Conventional MRI pituitary did not reveal any lesions. Therefore, CECT scan of the chest, abdomen and pelvis was performed in order to look for an ectopic source, which is usually a neuroendocrine tumour arising from pancreas or bronchus producing GHRH. CECT was also normal. She had secondary hypothyroidism with normal 9 am cortisol and prolactin (PRL- $131 \mathrm{mU} / \mathrm{L})$. Folliclear stimulating hormone (FSH), luteinizing hormone ( $\mathrm{LH})$ were raised as in normal post menopausal women (FSH- 28, LH-53 U/L). Her fasting blood sugar (FBS), hepatic transaminases and electro cardiogram (ECG) were normal.

\section{Case 2}

A 69 year old lady with past history of ovarian cancer, which was treated with total abdominal hysterectomy and bilateral salpingo-oophorectomy developed persistent low back ache and was referred to our unit for evaluation for osteoporosis. We noted that she had acromegaloid features such as enlarged lips, nose and prominent supraorbital ridges (Figure 1- No.2). Direct questioning revealed that she experienced excessive sweating and tightening of the wedding ring over the last 5 years. Acromegaly was confirmed by OGTT, which showed non suppressed GH. MRI pituitary was normal. CECT- chest, abdomen, which was done to exclude an ectopic source, did not reveal any abnormality. 24 hour urinary 5 hydroxy indol acitic acid (HIAA), which is usually raised in carcinoid tumours, was normal $(2.2 \mathrm{mg}\{3-17\})$. Rest of the anterior pituitary hormones were normal except FSH and LH, which were elevated due to menopause (LH- 52, FSH$66 \mathrm{U} / \mathrm{L})$. FBS, hepatic transaminases, ECG, colonoscopy were normal. DXA scan revealed osteopenia (T score of 2.4) and FRAX score showed a raised 10 year probability of hip fracture (4.5\%).

${ }^{1-3}$ National hospital of Sri Lanka. 


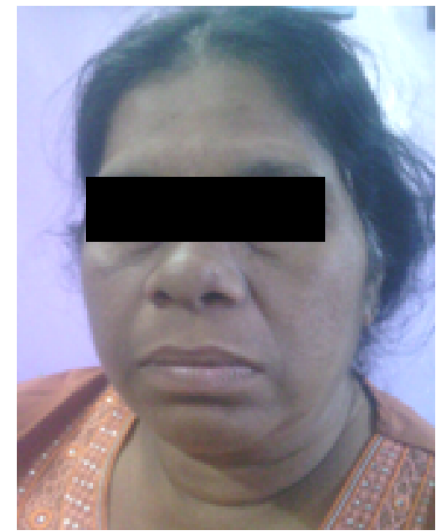

1

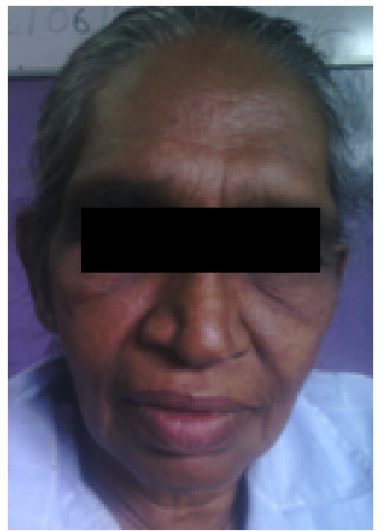

2

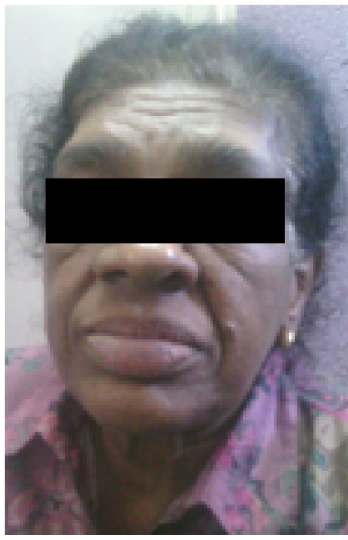

3

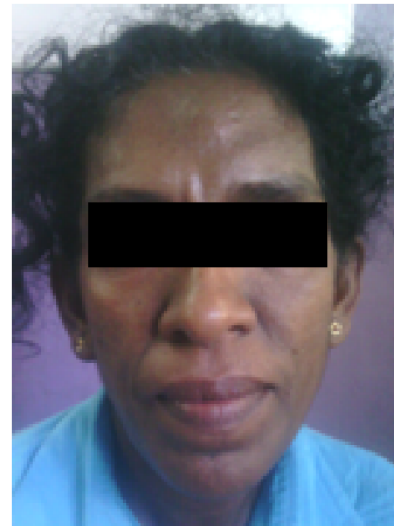

4

Figure 1. Facial appearances of patients 1-4.

\section{Case 3}

A 70 year old lady presented with change in facial appearance with acral enlargement over 5 years. She also noted deepening of voice and excessive sweating. She had hypertension and bilateral OA of knees, which required knee replacement. Features of acromegaly such as enlarged lips, nose and prominent supraorbital ridges were quite obvious in this patient (Figure 1 - No.3). OGTT showed non suppressed GH. MRI pituitary, CECT- chest, abdomen, and pelvis were normal. Her other anterior pituitary hormones were normal except the FSH, LH, which were elevated due to menopause (LH-47, FSH- $101 \mathrm{U} / \mathrm{L}$ ). She had impaired fasting glucose $(105 \mathrm{mg} / \mathrm{dl})$. Hepatic transaminases and ECG were normal. Colonoscopy revealed 2 large polyps, which were histologically tubular adenomatous polyps with grade 2 dysplasia.

\section{Case 4}

A 45 year old lady presented with change in facial appearance and excessive sweating over $1 \frac{1 / 2}{2}$ years. She also noted deepening of voice. She was amenorrhoeic for the past 10 months. On examination, she had obvious acromegaloid features such as coarse facial appearance with prominent supraorbital ridges, enlarged nose, lips and prognathism (Figure 1- No.4). Her blood pressure was elevated $(160 / 100 \mathrm{mmHg})$. OGTT showed non suppressed $\mathrm{GH}$, confirming the diagnosis of acromegaly. MRI pituitary, CECT of chest, abdomen, and pelvis were normal. FSH was raised $(25 \mathrm{U} / \mathrm{L})$ indicating that she is going in to menopause. However, LH response was inadequate (LH $8 \mathrm{U} / \mathrm{L}$ \{post menopausal: $>50\}$ ). Rest of the anterior pituitary hormones, FBS and ECG were normal.

All 4 patients described above did not have features of MEN-1, MacCune Albright syndrome, Carneys complex or Carcinoid syndrome. They had different clinical, biochemical and imaging findings (Table 1). Dynamic MRI pituitary was performed in 3 patients. It revealed micro adenomas in all 3 of them localizing the source of GH (Figure 2 and 3). One patient (No: 4) is awaiting dynamic MRI scan of the pituitary.

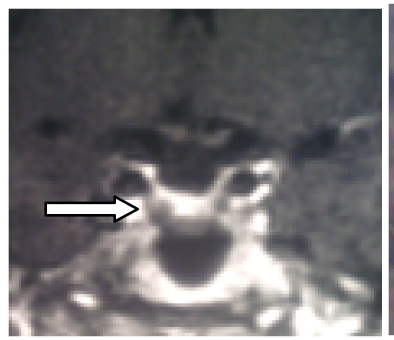

A

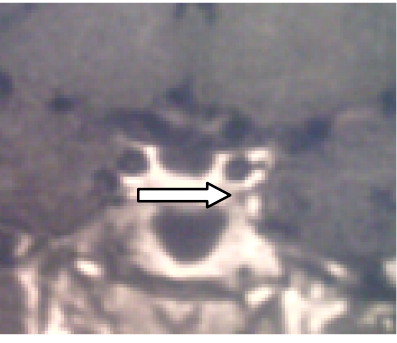

B
Figure 2. Gadolinium enhanced T1- weighted dynamic MR pituitary coronal image (patient no.1).

\section{A: At 60 sec-shows $4 \mathrm{~mm}$ hypointense lesion while normal pituitary is enhanced}

\section{B: At 240sec: lesion is enhanced, cannot diffe- rentiate from normal pituitary.}

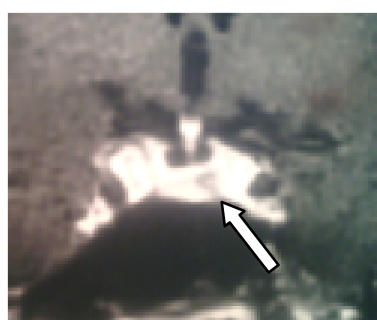

A

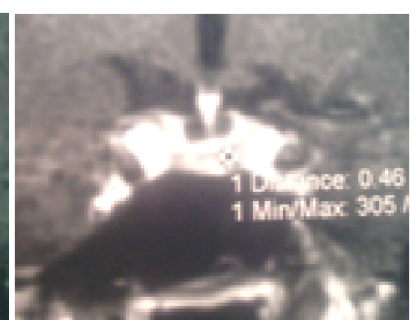

B
Figure 3. Gadolinium enhanced T1- weighted dynamic MR pituitary coronal image (patient no.2).

\section{A: At 60 sec-shows $5 \mathrm{~mm}$ hypointense Lesion.}

\section{$B$ : Lesion is marked on MRI film.}


Table 1. Clinical, biochemical and imaging characteristics of patients

\begin{tabular}{|c|c|c|c|c|c|c|c|c|}
\hline Patient No. & Age & $\begin{array}{l}\text { Time to } \\
\text { diagnosis } \\
\text { from } \\
\text { onset of } \\
\text { symptoms }\end{array}$ & $\begin{array}{l}I G F-1 \\
(\mathrm{ng} / \mathrm{ml})\end{array}$ & $\begin{array}{l}\text { Nadir } G H \\
(m U / L)\end{array}$ & $\begin{array}{l}\text { Ave.GH } \\
\text { on } G H D C^{*} \\
(m U / L)\end{array}$ & $\begin{array}{l}\text { CECT- } \\
\text { chest, } a b\end{array}$ & $\begin{array}{l}\text { Conventional } \\
M R I-\text { pit. }\end{array}$ & $\begin{array}{l}\text { Dynamic } \\
\text { MRI pit. } \\
\text { Size of } \\
\text { lesion }\end{array}$ \\
\hline 1 & 53 & 1 year & $\begin{array}{l}701 \\
(238)\end{array}$ & 4.5 & 4 & Normal & Normal & $4 \mathrm{~mm}$ \\
\hline 2 & 69 & 5 years & $\begin{array}{l}645 \\
(200)\end{array}$ & 17.6 & 13.98 & Normal & Normal & $5 \mathrm{~mm}$ \\
\hline 3 & 70 & 5 years & $\begin{array}{l}1153 \\
(200)\end{array}$ & 10.42 & $\mathrm{~N} / \mathrm{A}^{* *}$ & Normal & Normal & $6 \mathrm{~mm}$ \\
\hline 4 & 45 & $11 / 2$ years & $\begin{array}{l}656 \\
(267)\end{array}$ & 49 & 15 & Normal & Normal & $\begin{array}{l}\text { Awaiting } \\
\text { MRI }\end{array}$ \\
\hline
\end{tabular}

* GHDC-Growth hormone day curve

**NA- not available

\section{Discussion}

MRI is the best imaging modality in the evaluation of pituitary tumors. When a pituitary micro adenoma is suspected, dynamic contrast-enhanced techniques, which offer better tumor visualization should be employed $(4,5)$ Dynamic MRI involves obtaining a sequence of T1 weighted images at multiple time points after a bolus injection of intravenous gadolinium. The maximum image contrast between the normal pituitary tissue and microadenomas is attained about 30-60 seconds after the bolus injection of the intravenous contrast (6). Most of the microadenomas initially appear as relatively nonenhancing (dark) lesions within an intensely enhancing pituitary gland (7). The peak enhancement of the pituitary adenomas occurs after the most marked enhancement of the normal pituitary gland, and persists for a longer duration (7). Both spatial and temporal resolution must be sufficiently high in order to visualize a micro adenoma. At our institution, dynamic contrast pituitary captured 10 consecutive sets of images in coronal plane every 20-30 seconds (duration: 240 seconds). The thickness of a MRI slice was $0.9 \mathrm{~mm}$ with dynamic MRI, whereas that of a conventional MRI was $3 \mathrm{~mm}$. In our series of patients, dynamic MRI detected micro adenomas, which were not visualized with conventional MRI in all 3 patients. A special MRI sequence known as volumetric interpolated breath-hold examination MR imaging (VIBE with $1.2-\mathrm{mm}$ slice thickness) had been shown to be useful in detecting pituitary microadenomas in patients with acromegaly (8). Acromegaly with normal pituitary MRI poses a diagnostic challenge. Possible causes include a pituitary micro adenoma, which is not evident on imaging, MacCune Albright syndrome and ectopic source producing GHRH or very rarely $\mathrm{GH}$. Ectopic GHRH production giving rise to acromegaly is rare $(<1 \%)$. Sources of GHRH include neuroendocrine tumors arising from the pancreas, bronchi and appendix. According to a French nationwide series of 21 cases, these tumours were usually large $(10-80 \mathrm{~mm})$ by the time of the diagnosis and the primary tumor and/or metastases were identified by CECT chest /abdomen in nearly all cases (20 out of 21 ) (9). In one patient, the tumour was not identified by all imaging modalities used including $\mathrm{CT}$, [18F] fluorodeoxyglucose positron emission tomography scan and octreotide scan. Somatostatin receptor scintigraphy (SRS) using radiolabeled octreotide, performed for 16 patients, showed the primary tumor and/ or secondary lesions in $81 \%$ of patients. This study showed that CT scan was non inferior to SRS (sensitivity 81 vs. $86 \%$ ) in detecting ectopic GHRH secreting tumors. Most patients with ectopic GHRH secretion had enlarged pituitary rather than a normal pituitary on imaging. Their MRI may be normal or show either a adenoma or a micro cystic lesion. Therefore, in a patient with acromegaly and normal CECT chest and abdomen the possibility of an ectopic source may be very low. Surgical exploration of 
the pituitary gland in such patients had revealed GH secreting adenomas at surgery and led to the cure of the disease (8).

$\mathrm{GH}$-secreting tumor behavior is heterogeneous. It is interesting to note that some patients who had been symptomatic for many years may harbor small adenomas, which are not evident on imaging, whereas the majority has large invasive macroadenomas at the time of diagnosis. Daniel et al classified an acromegaly patient cohort (292 patients) according to clinical, radiological, histopathological characteristics and outcome (10). Three acromegaly types (1-3) were described, where the aggressiveness of the lesion increased from 1-3. Nonaggressive type 1 microadenomas had the most favorable outcome and occurred mostly in older patients. Histologicaly, these tumors were densely granulated and expressed immunoreactive p21 and somatostatin receptor 2 in abundance. Since resistance to medical treatment correlates inversely with SSTR2 abundance, these tumors are more treatment responsive (11).Densely granulated GH secreting adenomas were biologically more active and less aggressive than sparsely granulated adenomas, which occurred mostly in type 3 acromegaly patients (12).

In conclusion, localization of GH source may be challenging in a minority of the patients with acromegaly. Pituitary imaging is the first step in localizing the lesion. When the conventional MRI is negative, a dynamic MRI, which has a better spatial and temporal resolution, should be performed to detect a micro adenoma. If pituitary imaging is negative, chest and abdomen should be scanned with CECT to look for an ectopic source. It has been shown that ectopic GHRH secreting tumors are generally more than $1 \mathrm{~cm}$ in size and can be detected on CT in nearly all patients.

\section{References}

1. Colao A, Ferone D, Marzullo P, Lombardi G. Systemic complications of acromegaly: epidemiology, pathogenesis and management. Endocr Rev. 2004: 25: 102-52.
2. Dekkers OM, Biermasz NR, Pereira AM, Romijn JA, Vandenbroucke JP. Mortality in acromegaly: a metaanalysis. J Clin Endocrinol Metab. 2008: 93(1): 61-7.

3. Sano T, Asa SL, Kovacs K. Growth hormone-releasing hormone- producing tumors: clinical, biochemical, and morphological manifestations. Endocr Rev 1988: 9: 357-73.

4. Lee HB, Kim ST, Kim HJ, Kim KH, Jeon P, Byun HS, Choi JW. Usefulness of the dynamic gadolinium-enhanced magnetic resonance imaging with simultaneous acquisition of coronal and sagittal planes for detection of pituitary microadenomas. Eur Radiol. 2012: 22: 514-18.

5. Portocarrero-Ortiz L, Bonifacio-Delgadillo D, SotomayorGonza'lez A, Garcia-Marquez A, Lopez-Serna R. A modified protocol using half-dose gadolinium in dynamic 3-Tesla magnetic resonance imaging for detection of ACTH secreting pituitary tumors. Pituitary 2010:13: 230-5.

6. Chaudhary V, Bano S. Imaging of the pituitary: Recent advances Indian J Endocrinol Metab 2011; 15(13): 216-23.

7. Cheemum L, Walter K, Walter J M, Laurence E B. Magnetic resonance imaging of the brain and spine. Philadelphia: WW Lippincott Co; . The sella turcica and parasellar region 2002; 2: $283-362$.

8. Lonser R R, Kindzelski B A, Mehta G U , Jane J A, Oldfield E H. Acromegaly without Imaging Evidence of Pituitary Adenoma. J Clin Endocrinol Metab. 2010; 95: 4192-6.

9. Garby L, Caron P, Claustrat F, Chanson P, Tabarin A, Rohmer, et al. Clinical Characteristics and Outcome of Acromegaly induced by ectopic secretion of growth hormone-releasing hormone (GHRH): A French nationwide series of 21 cases. J Clin Endocrinol Metab. 2012; 97:2093104.

10. Cuevas-Ramos D, Carmichael J D, Cooper O, Bonert V S, Gertych A, Mamelak AN, Melmed S. A structural and functional acromegaly classification. $J$ Clin Endocrinol Metab. 2015; 100-1: 122-31.

11. Colao A, Auriemma RS, Lombardi G, Pivonello R. Resistance to somatostatin analogs in acromegaly. Endocr Rev. 2011; 32: $247-71$. 